\title{
Bases neurobiológicas de la drogadicción
}

\author{
E. Fernández-Espejo
}

\section{NEUROBIOLOGICAL BASIS OF DRUG ADDICTION}

\begin{abstract}
Summary. Introduction. Drugs of abuse cause addiction, characterized by compulsive and out of control drug use. Several neurochemical and molecular changes take place in the brain during the first phase of drug use which lead to dependence, addiction and drug abuse. Development. Every drug of abuse acts through similar neurophysiological mechanisms, mostly based on the abnormal activation of the mesolimbic dopamine system. Although the addicted brain tries to adapted to the drug action, there are permanent neural changes at the cellular and molecular levels which seem to underlie the addictive process and the emergence of abstinence symptoms after drug taking stops. Furthermore, these neural changes appear to subserve the emergence of cravings once the abstinent syndrome has been overcome. Cravings are the main factor leading to relapse, and they are often initiated by exposure to drug-related cues. [REV NEUROL 2002; 34: 659-64]
\end{abstract}

Key words. Adiction. Dependence. Dopamine. Drug. Mesolimbic system. Withdrawal.

\section{INTRODUCCIÓN}

Droga es toda sustancia natural o sintética que genera adicción, es decir, la necesidad imperiosa o compulsiva de volver a consumirla para experimentar la recompensa que produce, que es sensación de placer, euforia, alivio de la tensión, etc. Por tanto, las drogas inducen adicción y refuerzan la conducta asociada a su uso. El cese en el consumo de la droga adictiva induce abstinencia, conjunto de molestias emocionales y físicas que duran unos días, y cuya intensidad depende del tipo de droga. Evitar la abstinencia es también otra causa de búsqueda y recaída en la droga (reforzador negativo).

La diferencia de los términos dependencia y adicción es confusa. En realidad, la dependencia es el conjunto de cambios neurobiológicos que subyacen al consumo de la droga y que causan la adicción. Sin embargo, la adicción sería un grado elevado de dependencia (p. ej., la cafeína induce dependencia sin ser adictiva). En la presente revisión se utilizarán los términos dependencia y adicción de modo indistinto, según la terminología DSM, que considera que son sinónimos en lo que se refiere a las drogas adictivas. Atendiendo al grado de dependencia que generan, la Organización Mundial de la Salud (OMS) clasifica las drogas adictivas según la tabla; las drogas del grupo 1 son las que inducen mayor adicción.

Las bases neurobiológicas que subyacen a la drogodependencia son motivo de intenso estudio. La razón es clara: comprender qué induce la recompensa a la droga o qué cambios crónicos generan la adicción nos permitiría actuar terapéuticamente sobre estos procesos. Las bases neurobiológicas del proceso de drogadicción se estudian en cuatro grandes fases: estado de consumo agudo, estado de consumo crónico, abstinencia aguda y abstinencia a largo plazo [19]. Para cada fase hay datos morfofuncionales, neuroquímicos y moleculares, cuya integración nos permitirán, en un futuro, una compren-

Recibido: 30.10.01. Aceptadotras revisiónexternasinmodificaciones: 08.11.01. Profesor de Fisiología Médica. Departamento de Fisiología Médica. Facultad de Medicina. Universidad de Sevilla. Sevilla, España.

Correspondencia: Dr. Emilio Fernández Espejo. Departamento de Fisiología Médica. Facultad de Medicina. Universidad de Sevilla. Avda. Sánchez Pizjuán, 4.E-41009 Sevilla.Fax: +3495455 1768.E-mail: efespejo@us.es

(C) 2002, REVISTA DE NEUROLOGÍA sión más clara de los procesos neurobiológicos que originan la drogadicción. Los estudios se han realizado y se realizan tanto en animales de laboratorio como en el ámbito clínico. Fisiológica y bioquímicamente, se utilizan numerosas técnicas tendentes a cuantificar modificaciones en la respuesta electrofisiológica, lesiones neurales selectivas, histoquímica, marcadores proteicos, registro de liberación de neurotransmisores, etc., que no se van a detallar. Conductualmente, existen diversas pruebas de laboratorio que permiten estudiar el proceso de dependencia en roedores, en sus distintas vertientes, como la autoadministración de drogas, los tests de preferencia de lugar, de sensibilización conductual, etc. La autoadministración de drogas permite evaluar el aspecto consumidor en animales, mientras que los tests de preferencia de lugar permiten abordar el aspecto incentivo. En estos últimos, se establece un condicionamiento de contexto entre un lugar -el compartimento de un enclave, generalmente- y el consumo de droga, de modo que el animal tiende a buscar dicho lugar. En los tests de sensibilización se aborda el fenómeno de la sensibilización conductual, que se cree que resulta crítico en el proceso adictivo; el test de sensibilización locomotora es el que más se utiliza incremento progresivo de la conducta motora tras el consumo crónico de una droga-. Finalmente, el síndrome de abstinencia se evalúa tanto en sus aspectos somáticos (síntomas físicos y vegetativos) como emocionales (test de aversión de lugar). Recientemente, el empleo de ratones knock-out y trasgénicos ha abierto nuevas vías en el estudio del papel de los déficit génicos y proteicos selectivos en la adicción.

\section{ESTADO DE CONSUMO AGUDO: LAS DROGAS ADICTIVAS ACTÚAN SOBRE MECANISMOS NEUROFISIOLÓGICOS COMUNES}

El consumo agudo se refiere a los primeros contactos con la droga, a través de los cuales se establece el conocimiento de sus efectos placenteros y el aprendizaje tendente a su consumo. En el ser humano, mediante estudios con tomografía por emisión de positrones (PET), se sabe que el consumo agudo de psicoestimulantes, como cocaína o anfetamina, induce la activación de diversos centros nerviosos, entre los que destacan las vías mesolímbica y mesocortical, los núcleos del rafe y la amígdala (Fig. 1). En animales de experimentación se ha observado el 
mismo patrón de actividad tras la administración de drogas adictivas, no sólo psicoestimulantes, sino también opiáceos, nicotina o cannabinoides; se caracteriza por aumento de la expresión de c-Fos y de neuroaminas -principalmente dopamina (DA) o serotonina- en dichas áreas. Otras zonas, como el área gris periacueductal o el hipotálamo lateral, podrían involucrarse, pero ello no se ha demostrado todavía incuestionablemente [27].

Aunque las drogas adictivas presentan una gran diversidad molecular y actúan sobre diversos receptores y estructuras, existe un factor común a las mismas, que es la activación de la vía mesolímbica dopaminérgica, crítica en el proceso de dependencia y adicción [14,16,24]. Esta vía nace en el área tegmental ventral (ATV), y su activación durante el consumo agudo induce el incremento en la tasa de liberación de DA y una regulación al alza en los niveles de AMPc en el núcleo accumbens (NAC) y la amígdala extendi$\mathrm{da}$, áreas que se relacionan decisivamente con la recompensa y con el aprendizaje para el consumo [19,28]. Así, los psicoestimulantes (anfetamina y cocaína) incrementan directamente la liberación de DA en dicha vía, por medio de la inhibición del transportador de DA (ambas) o con el aumento de la exocitosis (anfetamina). Los opiáceos actúan sobre receptores opioides tipo mu e inhiben las interneuronas gabérgicas y estimulan las neuronas dopaminérgicas de la ATV. El alcohol y la nicotina activan los circuitos locales opioides de encefalinas del ATV y estimulan las neuronas del ATV. La nicotina también actúa directamente sobre receptores nicotínicos localizados en las neuronas del ATV y del NAC, y estimulan la actividad dopaminérgica mesolímbica -demostrado recientemente en humanos por Salokangas et al [23]-. Los cannabinoides actúan sobre receptores tipo CB1 localizados en las neuronas dopaminérgicas del ATV y NAC; la fenciclidina y el éxtasis aumentan la liberación de glutamato en el ATV, que, a su vez, estimula las neuronas dopaminérgicas. Los ansiolíticos benzodiacepínicos y el alcohol actúan sobre receptores tipo $\mathrm{GABA}_{\mathrm{A}}$ en el NAC y la corteza prefrontal, que, a su vez, modulan la actividad dopaminérgica (procedente del ATV) en dichas áreas. Los centros neurales que participan en el proceso adictivo se ilustran en la figura 2.

Se cree que la vía mesolímbica dopaminérgica participa, fisiológicamente, en la creación de hábitos de conducta tras estímulos reforzadores naturales (comida, bebida, sexo). La adicción sería, por tanto, una perturbación crónica de esta vía inducida por la droga, y se crearía un hábito patológico cuyo fin es el consumo de

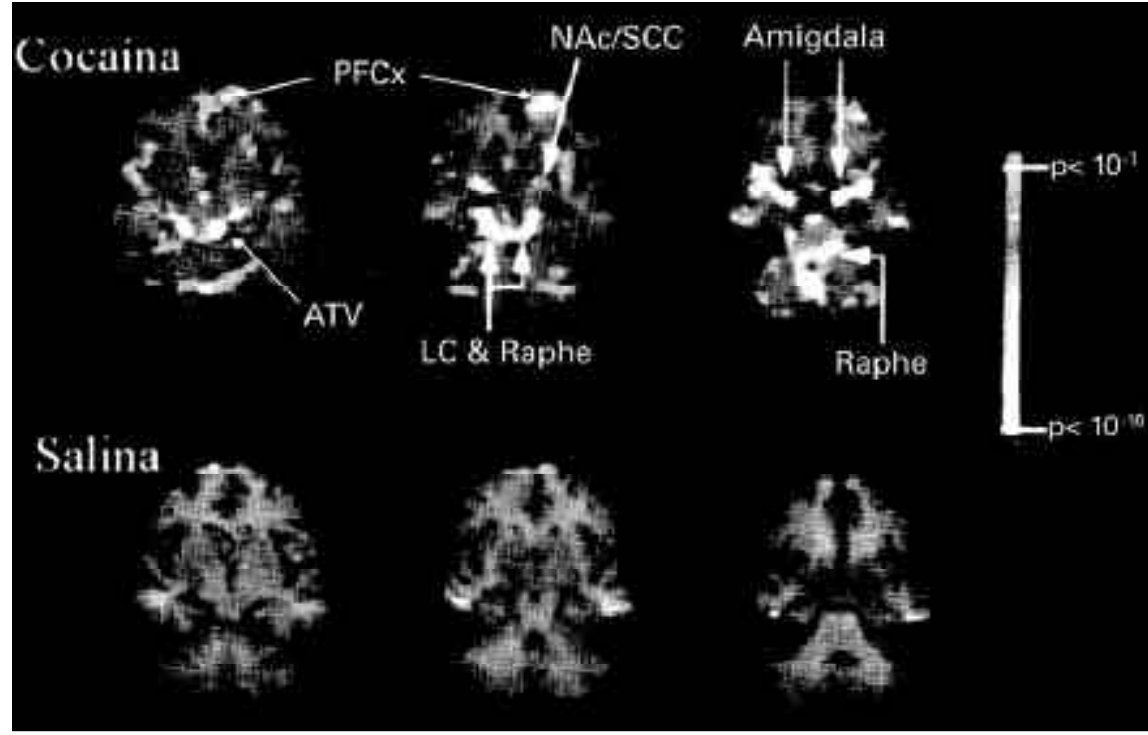

Figura 1 Activación de áreas cerebrales en el hombre tras el consumo agudo de cocaína, registrado mediante PET. Se observa que, mientras que la administración de salina no ocasiona cambios apreciables (abajo), la cocaína origina una señal de activación (más clara cuanta mayor intensidad) en zonas como el área tegmental ventral (ATV), la corteza prefrontal (PFCX), el núcleo accumbens (NAc), la amígdala extendida y los núcleos del rafe (modificado de [1]).

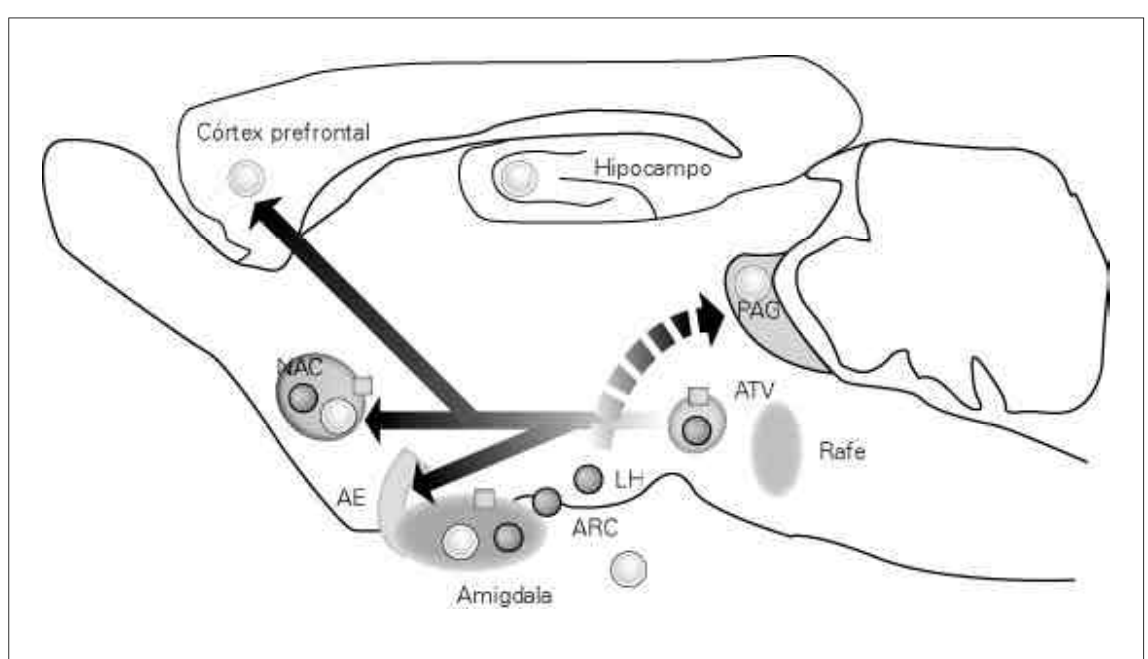

Figura 2. Centros y circuitos nerviosos que participan en la adicción a las drogas, en el cerebro de rata. La vía mesolimbicocortical dopaminérgica (línea continua gruesa) nace en el área tegmenta ventral (ATV) y se dirige al núcleo accumbens (NAC), la amígdala extendida (AE) y la córtex prefrontal, y es crítica en el proceso adictivo a las drogas. Los cuadrados representan la presencia de receptores nicotínicos. Los círculos oscuros representan la presencia de circuitos opiáceos locales. Los círculos periacueductal (PAG). Las vías serotoninérgicas cerebrales parten de los núcleos del rafe. El hipotálamo lateral (LH) y el núcleo arcuato (ARC), así como la vía betaendorfínica, que nace en dicho núcleo (línea discontinua) y que se dirige a la PAG, se cree que se involucran también en el proceso adictivo (modificado de [18]).

la droga (estímulo reforzador aberrante). La activación de la vía dopaminérgica mesocortical, que también nace en el ATV, ocasiona hiperactividad dopaminérgica en la corteza prefrontal, cuyo significado no está claro, pero que podría mediar en el proceso de aprendizaje y desarrollo del hábito asociado al consumo. Es evidente que el ATV desempeña un papel de primer orden en el desarrollo de la adicción y la dependencia (véase apartado siguiente).

Finalmente, los núcleos del rafe son la fuente principal de serotonina en el encéfalo, y su activación subyace al aumento en la liberación de serotonina en la fase aguda de consumo, que 


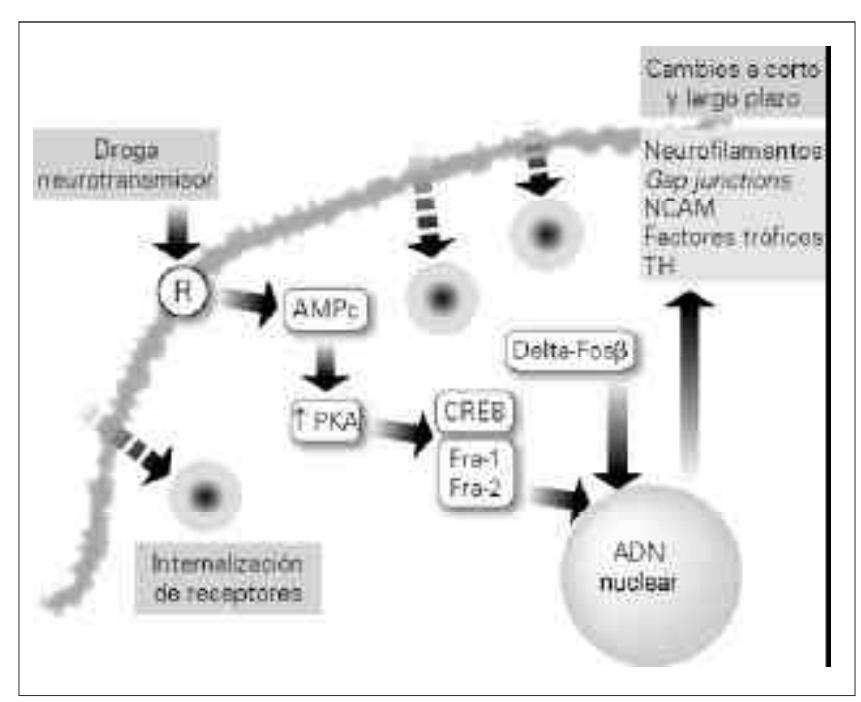

Figura 3. Cambios celulares durante la fase de consumo crónico de la droga. Las neuronas receptoras de la vía mesolímbica responden con internalización de receptores a la droga o neurotrasmisores involucrados, pero hay una regulación al alza de la vía de la adenilciclasa que ocasiona la activación génica y cambios celulares permanentes. AMPc: adeninmonofosfato cícliCO; PKA: proteincinasa A; CREB: CAMP-response-element-binding protein; $\mathrm{TH}$ : tirosinhidroxilasa.

Tabla. Clasificación de las drogas según su grado de dependencia.

\begin{tabular}{ll}
\hline Grupo 1 & Opio y derivados \\
\hline Grupo 2 & Barbitúricos y alcohol \\
\hline Grupo 3 & Psicoestimulantes (cocaína, anfetamina), éxtasis, fenciclidina \\
\hline Grupo 4 & Cannabis y derivados, mescalina, LSD, nicotina \\
\hline
\end{tabular}

parece ser que participa en fenómenos de recompensa en el NAC y la corteza frontal, en paralelo a la hiperactividad dopaminérgica, principalmente tras el consumo de psicoestimulantes (cocaína, anfetamina) y éxtasis [15].

\section{ESTADO DE CONSUMO CRÓNICO: EXISTE UNA NEUROADAPTACIÓN, PERO HAY CAMBIOS CELULARES PERMANENTES}

Experimentalmente, se han investigado los efectos neurobiológicos sobre la vía mesolímbica dopaminérgica del consumo crónico de opiáceos y psicoestimulantes, y la exposición versará sobre los conocimientos acumulados tras el empleo de dichas drogas. Durante el consumo crónico tienen lugar fenómenos de neuroadaptación, que podrían representar una reacción del organismo tendente a retomar la homeostasis o equilibrio orgánico, fundamental para la vida. Sin embargo, hay cambios críticos intracelularmente y se desarrolla una sensibilización en la liberación de DA mesolímbica, hechos que resultan de gran importancia en el establecimiento de la dependencia crónica y de la abstinencia tras el cese del consumo (Fig. 3).

En animales de experimentación y estudios post mortem del cerebro de adictos a opiáceos, se ha detectado que el consumo crónico se suele acompañar de una disminución del número de receptores celulares que responden a la droga (tras su internalización) en las neuronas de la vía mesolímbica, y no hay aumento del AMPc en centros neurales como el NAC o la amígdala, al contrario de lo que sucede en la fase de consumo agudo. Estos efectos representan fenómenos de neuroadaptación. Sin embargo, los componentes intracelulares de la vía de señalización de la adenilciclasa se regulan al alza: se detecta un aumento en los niveles de proteincinasa A (PKA) y de factores de transcripción CREB (del ingles, cAMP-responseelement-binding protein), Fra-1, Fra- 2 y delta-Fos $\beta$, tres factores de trascripción de la familia Fos [14,24]. Se cree que la mayor concentración de PKA podría deberse a un déficit en su degradación, pues el AMPc no se encuentra regulado al alza. La mayoría de los factores comentados se regulan al alza de modo transitorio, por lo que su papel en los cambios crónicos asociados a la adicción se ha cuestionado, excepto el factor delta-Fos $\beta$, que se acumula progresivamente en el cerebro con el consumo repetido de la droga.

Los mediadores comentados participan en la activación de genes nucleares, cuyos efectos no se conocen con precisión, pero se sabe que intervienen en la remodelación sináptica. Así, se expresan factores neurotróficos estimuladores y proteínas de agregación NCAM, que inducen la formación de nuevos contactos sinápticos y gap junctions. Por ejemplo, en el ATV existen factores neurotróficos estimuladores e inhibidores que mantienen un equilibrio trófico en situación normal, pero durante el desarrollo de la dependencia se detecta, en ratas, un desajuste del equilibrio a favor de factores estimuladores (véase siguiente apartado). Se ha descrito la aparición de nuevas sinapsis en el ATV y gap junctions en el NAC tras el consumo crónico de heroína en ratas. No se sabe hasta qué grado esto subyace al desarrollo de la adicción, pero debe desempeñar un papel relevante, pues el establecimiento de gap junctions es prácticamente irreversible. En el caso de drogas opiáceas, no existe internalización de receptores opiáceos mu, lo que podría relacionarse con la fuerte dependencia que ocasionan estas drogas y con la gran hiperactivación crónica de las vías de señalización intracelulares, como el excesivo recambio (turnover) de proteínas G. Este defecto en la internalización no aparece tras la estimulación con opiáceos endógenos [26], lo que indica una diferencia crítica entre opiáceos endógenos no adictivos y opiáceos adictivos de origen exógeno.

\section{El área tegmental ventral y la adicción mediada por sensibilización}

Estudios experimentales en roedores han puesto de manifiesto que la administración o exposición repetida a drogas opiáceas y psicoestimulantes da lugar a un incremento progresivo de sus efectos conductuales y de recompensa, fenómeno llamado 'sensibilización conductual', lo que puede observarse incluso tras años del cese del consumo de la droga $[10,12,20,25]$. Como se ha comentado, numerosos estudios indican que este fenómeno de sensibilización parece mediarse por el sistema mesolímbico dopaminérgico, que nace en el ATV y se dirige a áreas de control motor y límbico, como el NAC y la amígdala, regiones cerebrales que median numerosos procesos emocionales y de aprendizaje motor [11,22,27]. La administración aguda de diversas drogas, como se ha comentado, incrementa la liberación de DA en dichas áreas, y esta liberación se refuerza con el consumo crónico de la droga, lo que se denomina 'sensibilización dopaminérgica' [7,14,24], fenómeno paralelo a la 'sensibilización conductual'. Esto último representa un hecho crucial de las drogas adictivas y diferencial respecto a reforzadores naturales 


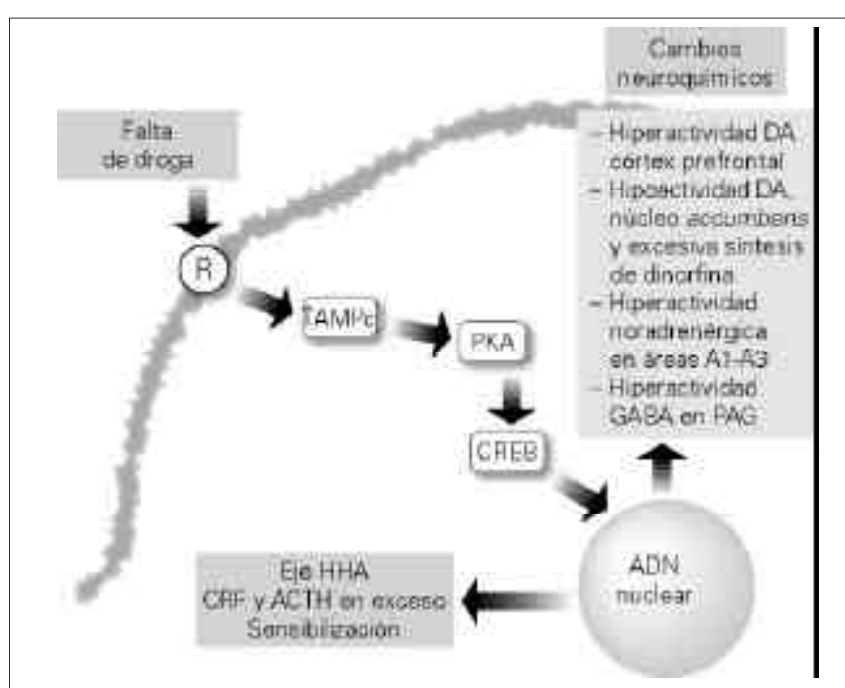

Figura 4. Cambios celulares durante la abstinencia. La vía de la adeniIciclasa se activa mucho, con regulación al alza de AMPc, lo que es crítico en la aparición de los principales cambios neuroquímicos del síndrome de abstinencia que subyacen a la sintomatología, tanto somática como emocional, que le acompaña. Eje HHA: eje hipotálamohipofisario-adrenal; ATV: área tegmental ventral; AMPC: adenosinmonofosfato cíclico; PKA: proteincinasa A; DA: dopamina; GABA: ácido gamma-aminobutírico; CRF: factor liberador de corticotropina; ACTH: hormona adrenocorticotropa.

(comida, bebida, actividad sexual), donde no hay sensibilización dopaminérgica. Por tanto, parece que la sensibilización subyace al desarrollo de la adicción a drogas y, con toda seguridad, a la abstinencia y recaída tras el cese del consumo.

Hay dos fenómenos morfoneuroquímicos básicos en el proceso de la sensibilización: 1 . El proceso se inicia por cambios permanentes sinápticos en el ATV; 2 . Estos cambios se median por el incremento de la actividad de glutamato en dicha área, que, a su vez, sensibiliza los receptores $\mathrm{D}_{1}$ de DA y origina una respuesta aumentada de las neuronas dopaminérgicas de esta región [2,3,9]. Por tanto, el glutamato da lugar a fenómenos de neuroplasticidad que ocasionan la sensibilización. El incremento de la actividad dopaminérgica en ATV también se pone de manifiesto por el aumento de marcadores glutamatérgicos, como los receptores NMDR 1 sitos en neuronas de DA, y de la expresión de tirosina-hidroxilasa (TH). Además, en el NAC, diana del ATV, se detecta un incremento en la expresión de AMPc, PKA, y delta-Fos $\beta$ [17]. Actualmente, no se conocen los mediadores moleculares de dichos fenómenos, pero existen evidencias de que factores neurotróficos liberados en la ATV en respuesta al glutamato podrían participar en los cambios sinápticos permanentes, tales como el factor básico de crecimiento fibroblástico (bFGF, en inglés), el factor neurotrófico derivado de cerebro (BDNF), la neurotrofina 3 (NT-3) o el factor neurotrófico de origen glial (GDNF) [8,17,21]. La acción de factores neurotróficos mediaría cambios permanentes en el circuito neuronal del ATV, como modificaciones en el tamaño neuronal, desarrollo de filamentos gliales, atrofia de neurofilamentos, etc. [17]. De hecho, en circuitos relacionados con la memoria/aprendizaje, estos cambios plásticos debidos a factores neurotróficos acompañan a tareas de aprendizaje a largo plazo. Esto supone un interesante paralelismo entre la adicción y los procesos de memoria/aprendizaje, donde subyacen cambios plásticos de circuitos neuronales [27]. La acción de los

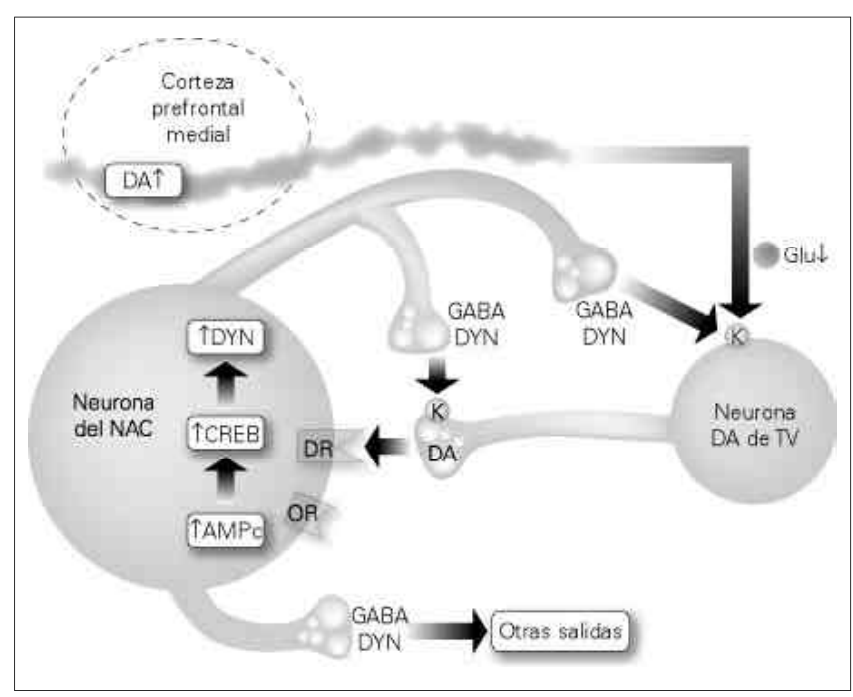

Figura 5. Bases neurobiológicas conocidas de la disforia del síndrome de abstinencia opiáceo. Durante el síndrome de abstinencia hay una regulación al alza del AMPC y mediadores de su vía en las neuronas de proyección del núcleo accumbens (NAC), lo que conlleva expresión génica y síntesis de dinorfinas. Este opiáceo endógeno se libera en las terminales sinápticas que inervan el ATV, y actúa sobre receptores kappa. La acción agonista kappa inhibe la actividad neuronal y, por tanto, la liberación dopaminérgica de las terminales del área tegmental ventral (ATV) en el NAC. Este fenómeno participaría en la profunda hipoactividad dopaminérgica detectada en el NAC durante la abstinencia opiácea. Además, estudios realizados en nuestro laboratorio en roedores permiten afirmar que la hiperactividad dopaminérgica en corteza prefrontal medial, propia del síndrome de abstinencia, inhibe la liberación de glutamato (Glu) de las terminales corticales en el ATV [5]. El glutamato es excitador, por lo que la disminución en su liberación ocasionaría también una disminución de la actividad neuronal del ATV; por tanto, participaría en la hipoactividad dopaminérgica en el NAC (modificado de [18]).

factores neurotróficos es dual: algunos parecen inducir sensibililización, y otros, la antagonizan. Así, la administración de BDNF o GDNF en el ATV ocasiona el bloqueo de la sensibilización a la morfina o cocaína en ratas. Sin embargo, la infusión de bFGF o NT-3 ocasiona un aumento de la sensibilización a la morfina o cocaína [8].

\section{ABSTINENCIA AGUDA: LOS CAMBIOS CELULARES DE LA FASE DE CONSUMO CRÓNICO ORIGINAN LA SINTOMATOLOGÍA AL CESAR EL CONSUMO DE DROGA}

Los cambios celulares antes comentados participarían también en la emergencia de los síntomas de la abstinencia tras el consumo de droga. Además, hay fenómenos de rebote morfofuncional y neuroquímicamente. Entre ellos, destaca el incremento agudo de AMPc mesolímbico y amigdalino y, en consecuencia, de los mediadores intracelulares que participan en su vía (Fig. 4). Los cambios serían responsables de la sintomatología somática (conductual y vegetativa) y emocional de la abstinencia. En el ser humano, el cuadro clínico es de mayor o menor gravedad según el tipo de droga. Así, los opiáceos inducen una abstinencia florida con anhedonia, depresión, temblor, sudación, molestias abdominales, diarrea, hipertensión, etc. El alcohol puede producir cuadros delirantes e intensa sintomatología vegetativa. Otras drogas, como la cocaína, producen cuadros de abstinencia más leves.

Respecto a las drogas opiáceas y psicoestimulantes, morfofuncional y neuroquímicamente, tanto en humanos como ani- 
males de experimentación, se ha observado una hiperactividad en áreas mesolímbicas, de modo semejante a lo que sucede en la fase de consumo, sobre todo la amígdala y amígdala extendida, así como en otras áreas como el locus ceruleus, la sustancia gris periacueductal y el hipotálamo. Los cambios en las áreas límbicas se relacionarían con la sintomatología emocional del síndrome, mientras que los otros centros participarían en la sintomatología somática (conductual y autónoma) de la abstinencia [13]. Los cambios neuroquímicos mesolímbicos parece ser que se asemejan en otras drogas que ocasionan un marcado síndrome de abstinencia, como el alcohol y los benzodiacepínicos [16].

Respecto a las drogas opiáceas, en las que se ha centrado el estudio de nuestro laboratorio, durante el síndrome agudo de abstinencia en ratas se detecta un gran aumento de DA en la corteza prefrontal, junto a una depresión acentuada de la liberación de DA en el NAC. Nuestros estudios y los de otros autores permiten postular que los cambios en la corteza prefrontal son de naturaleza dual, tanto compensatoria como agravante del síndrome. Así, el aumento de DA prefrontal disminuye la gravedad somática del síndrome (ejemplo de mecanismo homeostático), pero, de modo reactivo, disminuye la actividad dopaminérgica en el NAC, lo que es un hecho importante en el desarrollo de la disforia emocional propia del síndrome de abstinencia [18]. Otros autores han confirmado que la disforia se relaciona con hipoactividad dopaminérgica en el NAC, pero que ésta también se debe al aumento de AMPc intracelular en dicho núcleo, que ocasiona la liberación de dinorfinas que actúan sobre receptores kappa del ATV inhibiendo la actividad de las neuronas dopaminérgicas en esta región (Fig. 5). En resumen, la disforia, que es un signo cardinal de la abstinencia, parece mediarse por una disminución de la actividad dopaminérgica mesolímbica, causada tanto por la liberación de dinorfinas desde las terminales del NAC en el ATV, como por una acción inhibitoria de origen prefrontal.

Además, se detecta un aumento de la tasa de liberación de serotonina en la amígdala extendida y en la corteza cerebral. Estudios realizados en nuestro laboratorio, tras lesiones casi completas de los núcleos del rafe (fuente principal de serotonina cerebral) en ratas, indican que no se altera el síndrome de abstinencia opiáceo en su aspecto somático, pero sí se agrava el síndrome emocional y aversivo; ello indica que la serotonina ejerce una acción antidisfórica, de naturaleza homeostática, durante el síndrome de abstinencia opiáceo. Sin embargo, se incrementa casi 10 veces el efecto protector de la clonidina en el síndrome disfórico [4]. Este hecho puede ser importante como fundamento para el empleo de fármacos con posible acción beneficiosa sobre la disforia, como bloquedores selectivos de receptores de serotonina, cuyo efecto se estudia ahora.
Por otra parte, se sabe que existe un importante aumento de la actividad noradrenérgica cortical y límbica durante la abstinencia, que se relaciona con la gravedad del síndrome. De hecho, el bloqueo de la hiperactividad noradrenérgica mediante fármacos como la clonidina, es capaz de atenuar significativamente la sintomatología del síndrome de abstinencia. Antes se creía que este fenómeno se debía a una hiperactividad en el locus ceruleus, fuente principal de noradrenalina del cerebro. Sin embargo, nuestros estudios han permitido demostrar que dicho núcleo no desempeña un papel relevante [5], pues su destrucción no altera el síndrome de abstinencia opiáceo. Otros autores han detectado que la actividad noradrenérgica que se origina en los núcleos noradrenérgicos espinales (A1-A2) e incide principalmente en la amígdala extendida, sí es clave en la sintomatología somática del síndrome de abstinencia [6]. Finalmente, en el área gris periacueductal se detecta una hiperactividad gabérgica, que podría relacionarse con la gravedad vegetativa del síndrome, junto con el aumento de la actividad del eje hipotálamo-hipofisario-adrenal (HHA), que se manifiesta por el aumento de factor liberador de corticotropina (CRF) y de hormona adrenocorticotropa (ACTH) sanguínea, así como de corticoides sanguíneos.

\section{ABSTINENCIA A LARGO PLAZO: LA RECAÍdA}

Una vez que el sujeto ha superado la fase aguda de abstinencia, comienza la fase asintomática de abstinencia a largo plazo. Durante dicha fase, el sujeto puede superar definitivamente su drogadicción con apoyo médico y psicoterápico adecuado, pero tienen lugar fenómenos importantes que suelen originar la recaída de un número importante de sujetos en el consumo de la droga: el 'ansia de droga' (craving, en inglés) y la 'abstinencia condicionada'. Estos fenómenos presentan un marcado carácter psicológico. Durante el ansia de droga, el sujeto presenta deseos imperiosos de volver a consumir la droga, y durante la abstinencia condicionada aparece sintomatología abstinente, a veces sin razón aparente. Ambos fenómenos se disparan, podríamos decir, en situaciones ambientales y emocionales determinadas, como estrés, recreación de lugares asociados al consumo anterior, etc. No se conocen las bases neurobiológicas de este fenómeno, pero se sabe que se relaciona con el proceso de sensibilización de la fase de consumo crónico de la droga, que, como se ha explicado, origina cambios permanentes de los circuitos mesolímbicos. Además, existe una hiperreactividad del eje HHA que puede durar años, y que explica la liberación exagerada en estos sujetos de CRF, ACTH y corticoides suprarrenales durante situaciones de estrés. Además, estas hormonas pueden agravar la sensibilización de los circuitos dopaminérgicos y facilitar la posterior aparición de ansias de droga [18].

\section{BIBLIOGRAFÍA}

1. Breiter HC, Rosen BR. Functional magnetic resonance imaging of brain reward circuitry in the human. In McGinty J, ed. Advancing from the ventral striatum to the extended amygdala. New York: Annals NY Academy Sci; 1999. p. 523-47.

2. Cador M, Bjijou Y, Stinus L. Evidence of a complete independence of the neurobiological substrates for the induction and expression of behavioral sensitization to amphetamine. Neuroscience 1995; 65: 385-95.

3. Cador M, Bjijou Y, Cailhol S, Stinus L. D-amphetamine-induced behavioral sensitization: implication of a glutamatergic medial prefrontal cortex-ventral tegmental area innervation. Neuroscience 1999; 94 : 705-21.

4. Caillé S, Fernández-Espejo E, Stinus L. Involvement of serotonin neu- rotransmission in opiate dependence. Behav Pharmacology 1999; 10: S14.

5. Caillé S, Fernández-Espejo E, Reneric JP, Cador M, Koob GF, Stinus L. Total neurochemical lesion of noradrenergic neurons of the locus coeruleus does not alter either naloxone-precipitated or spontaneous opiate withdrawal nor does it influence the ability of clonidine to reverse opiate withdrawal. J Pharmacol Exp Therap 1999; 290: 881-92.

6. Delfs JM, Zhu Y, Druhan JP, Aston-Jones G. Noradrenaline in the ventral forebrain is critical for opiate withdrawal-induced aversion. Nature 2000; 430: 430-4.

7. Di Chiara G, Tanda G, Bassareo V, Pontieri F, Acquas E, Fenu S, et al. Drug addiction as a disorder of associative learning: role of nucle- 
us accumbens shell/extended amygdala. In McGinty J, ed. Advancing from the ventral striatum to the extended amygdala. New York: Annals NY Academy Sci; 1999. p. 461-85.

8. Flores C, Stewart J. Basic fibroblast growth factor as a mediator of the effects of glutamate in the development of long-term sensitization to stimulant drugs: studies in the rat. Psychopharmacology 2000; 151 : 152-65.

9. Kalivas PW, Weber B. Amphetamine injection in the ventral mesencephalon sensitizes rats to peripheral amphetamine and cocaine. J Pharmacol Exp Ther 1988; 245: 1095-102.

10. Kalivas PW, Duffy P. Time course of extracellular dopamine and behavioral sensitization to cocaine. J Neurosci 1993; 13: 266-75.

11. Kalivas PW, Stewart J. Dopamine transmission in the initiation and expression of drug -and stress- induced sensitization of motor activity. Brain Res Rev 1991; 16: 223-44.

12. Kolta MG, Shreve P, DeSouza V, Uretsky NJ. Time course of the development of the enhanced behavioral and biochemical responses to amphetamine after pretreatment with amphetamine. Neuropharmacology 1985; 24: 823-9.

13. Koob GF, Maldonado R, Stinus L. Neural substrates of opiate withdrawal. TINS 1992; 15: 186-91.

14. Leshner AI. Addiction is a brain disease, and it matters. Science 1997; 278: $45-7$.

15. Liechti ME, Vollenweider FX. Acute psychological and physiological effects of MDMA ('Ectasy') after haloperidol treatment in healthy humans. Eur Neuropsychopharmacol 2000; 10: 289-95.

16. Melichar JK, Daglish MRC, Nutt DJ. Addiction and withdrawal-current views. Curr Opin Pharmacol 2001; 1: 84-90.

17. Messer CJ, Eisch AJ, Carlezon WA, Whisler K, Shen L. Role for GDNF in biochemical and behavioral adaptations to drugs of abuse. Neuron 2000; 26: 247-57.

\section{BASES NEUROBIOLÓGICAS DE LA DROGADICCIÓN}

Resumen. Introducción. Las drogas de abuso causan adicción, la cual se caracteriza por el consumo compulsivo y fuera de control de las drogas. Durante la primera fase del consumo, tienen lugar en el cerebro diversos cambios neuroquímicos y moleculares, que llevan a la dependencia y a la adicción. Desarrollo. Todas las drogas adictivas actúan a través de mecanismos neurofisiológicos comunes, principalmente basados en la activación anómala del sistema mesolímbico dopaminérgico. Aunque el cerebro del adicto trata de adaptarse a la acción de la droga, hay cambios permanentes a nivel celular y molecular que subyacen al proceso adictivo y a la aparición de síntomas de abstinencia tras el cese del consumo de la droga. Además, estos cambios neurales parece que participan en la aparición del 'ansia de droga' o craving tras la abstinencia, que es un deseo incontrolado de droga, principal causa de recaída y que a menudo se inicia por estímulos asociados a la droga. [REV NEUROL 2002; 34: 659-64] Palabras clave. Abstinencia. Adicción. Dependencia. Dopamina. Droga. Sistema mesolímbico.
18. Nestler EJ. Molecular basis of long-term plasticity underlying addiction. Nature Reviews Neurosci 2001; 2: 119- 28.

19. Nestler EJ, Aghajanian GK. Molecular and cellular basis of addiction. Science 1997; 278: 58-63.

20. Piazza PV, Deminière JM, LeMoal M, Simon H. Factors that predict vulnerability to amphetamine self-administration. Science 1989; 245 : 1511-3.

21. Pierce RC, Pierce-Bancroft AF, Prasad BM. Neurotrophin-3 contributes to the initiation of behavioral sensitization to cocaine by activating the Ras/Mitogen-activated protein kinase signal transduction cascade. J Neurosci 1999; 19: 8685-95.

22. Robinson TE, Becker JB. Enduring changes in brain and behavior produced by chronic amphetamine administration: a review and evaluation of animal models of amphetamine psychosis. Brain Res Rev 1986; 396: 157-98.

23. Salokangas RK, Vilkman H, Ilonen T, Taiminen T, Bergman J, Haaparanta M, et al. High levels of dopamine activity in the basal ganglia of cigarette smokers. Am J Psychiatry 2000; 157: 632-4.

24. Shippenberg TS, Elmer GI. The Neurobiology of opiate reinforcement. Critical Reviews in Neurobiology 1998; 12: 267-303.

25. Vezina P, Pierre P, Lorrain D. The effect of previous exposure to amphetamine on drug-induced locomotion and self-administration of a low dose of the drug. Psychopharmacology 1999; 147: 125-34.

26. Whistler JL, Chuang HH, Chu P, Jan LY, Von Zastrow M. Functional dissociation of mu opioid receptor signaling and endocytosis: implications for the biology of opiate tolerance and addiction. Neuron 1999; 23: 737-46.

27. Wise RA. Opiate reward: sites and substrates. Neurosci Biobehav Rev 1998; 13: 129-33.

28. Wise RA. Addiction becomes a brain disease. Neuron 2000; 26: 27-33.

\section{BASES NEUROLÓGICAS DA HABITUAÇÃO A DROGAS}

Resumo. Introdução. As drogas de abuso causam habituação, a qual é caracterizada pelo consumo compulsivo e descontrolado das mesmas. Durante a primeira fase do consumo, têm lugar diversas alterações neuroquímicas e moleculares no cérebro, que levam à dependência e à habituação. Desenvolvimento. Todas as drogas de habituação actuam através de mecanismos neurofisiológicos comuns, principalmente baseados na activação anómala do sistema mesolímbico dopaminérgico. Embora o cérebro do toxicodependente se adapte à acção da droga, existem alterações permanentes a nível celular e molecular subjacentes ao processo de habituação e ao aparecimento de sintomas de abstinência após a cessação de consumo da droga. Além disso, estas alterações neuronais parecem participarno aparecimento da 'ânsia da droga'(craving), principal causa de recaída e que frequentemente se inicia por estímulos associados à droga. [REV NEUROL 2002; 34: 659-64]

Palavras chave. Abstinência. Dependência. Dopamina. Droga. Habituação. Sistema mesolímbico. 